Pedagogía y Saberes n. ${ }^{\circ} 53$

Universidad Pedagógica Nacional

Facultad de Educación. 2020. pp. 111-120

\title{
Alienación, enseñanza y separación del Otro*
}

Artículo de reflexión

Alienation, Teaching and Separation from the Other Alienação, ensino e separação do Outro

Aída Sotelo Céspedes**

\section{Para citar este artículo:}

Sotelo, A. (2020). Alienación, enseñanza y separación del Otro. Pedagogía y Saberes, 53, 111-120. https://doi.org/10.17227/ pys.num53-10568

* El presente texto es producto de una reflexión realizada a partir de mis observaciones durante mi experiencia como enseñante y la lectura de elaboraciones de psicoanalistas, enseñantes y filósofos sobre la enseñanza y la lógica social.

** Magister en Estudios Sociales. Docente Ocasional de tiempo completo de la Universidad Pedagógica Nacional.

Correo electrónico: csotelo@pedagogica.edu.co

Código Orcid: http://orcid.org/0000-0001-6958-8429 


\title{
Resumen
}

Este texto, producto de mi reflexión, describe el proceso de sometimiento al lenguaje que constituye al sujeto, para dar importancia a la diferencia entre sus dos fases: 1) el sujeto hablado se aliena en los significantes del primer Otro, 2) separarse de esos significantes lo libera. El caso de los hermanos Castaño Gil en Colombia, tal como lo relata Manuel Castaño, permite preguntar si una enseñanza movilizaría la alienación inicial del sujeto al gran Otro del lenguaje transmitido por la familia, es decir, si haría alguna separación. Separación, que en el concepto psicoanalítico que aquí pretendo examinar.

\section{Palabras clave}

alienación; separación; Otro; enseñanza; saber

\begin{abstract}
This text, product of my reflection describes the process of subjugation to language that constitutes the subject, to give importance to the difference between its two phases: 1) the talked subject alienates himself in the first Other signifiers, 2) to separate himself from those signifiers liberates him. The case of Castaño Gil brothers in Colombia, as recounted by Manuel Castaño, allows us to ask if teaching would move the initial alienation from the Other of language transmitted by the family, would it produce any separation. Separation which is the psychoanalytic concept that I intend to examine here.
\end{abstract}

\section{Keywords}

alienation; separation; other; teaching; wisdom

\section{Resumo}

Este texto produto da minha reflexão descreve o processo de subjugação da linguagem que constitui o sujeito, para dar importância à diferença entre as duas fases: 1) o sujeito falado se aliena nos significantes do primeiro Outro, 2) separar-se de esses significantes o libera. 0 caso dos irmãos Castaño Gil na Colômbia, conforme relatado por Manuel Castaño, permite-nos perguntar se um ensino mobilizaria a alienação inicial da disciplina do grande Outro da língua transmitida pela família, isto é, produziria alguma separação. Separação, que é o conceito psicanalítico que pretendo examinar aqui.

\section{Palavras chave}

alienação; separação; Outro; ensino; sabedoria 
La única enseñanza verdadera es la que consigue despertar en quienes escuchan una insistencia, ese deseo de conocer que solo puede surgir cuando ellos mismos y también el que les enseña han evaluado la ignorancia, en tanto ella, como tal es fecunda.

Jacques Lacan (1978a, p. 242)

\section{Pregunta inicial}

Tanto la educación como la clínica psicoanalítica constituyen acontecimientos de palabra, cada una de ellas tiene la estructura de un discurso en el sentido lacaniano del término, es decir, de un tipo de vínculo social; son modos de articulación significante, lazos de dominio, con sus respectivos productos e imposibilidades. Hubo un periodo en que los lazos parecieron estrecharse, cuando los descubrimientos de Freud se dieron a la luz, por el entusiasmo entre quienes se interesaban por la infancia, ante lo que pudiera lograr una educación donde se aplicaran las elaboraciones recientemente expuestas. Algunos creían que una educación de inspiración psicoanalítica sería liberadora. En 1979, Catherine Millot analizó la historia de esos intentos de fusión y de la separación final de los dos discursos, que hoy reconocemos muy distintos.

No obstante, conservada esa distancia, propongo examinar aquí si en el proceso de sujeción al lenguaje, imprescindible en la constitución del humus humano, hay una enseñanza que opera efectos de separación entre el sujeto y el Otro al que se había alienado inicialmente.

\section{Alteridad y negatividad}

En la hipermodernidad la subjetividad se identifica cómodamente con interioridad del individuo susceptible de llenarse con contenidos. Así pues, en esta lógica de las positividades, la formación aparece como sumatoria, posesión, apropiación de contenidos. Sin embargo, ningún contenido positivo puede decir lo que es del sujeto.

[...] la identidad del sujeto es en principio negativa. Así, por ejemplo, al nombre propio se le encarga decir lo que yo soy. Pero, él no es sino una concha vacía. Dice solo que yo soy, el lugar donde soy en $\mathrm{mi}$ genealogía, pero, no comporta ningún contenido. Por el contrario, la inscripción de esta negatividad constituyente es lo que permite a un individuo existir como sujeto. (Lebrun, 2019, p. 45)

De acuerdo con Lebrun, es posible decir entonces que, de no tener en cuenta esta negatividad, tratamos con un individuo y no con un sujeto, ya que el individuo es un sujeto al cual se han amputado sus lazos sociales. A partir de aquí, la práctica pedagógica y el psicoanálisis toman distintos caminos. Este último considera el lenguaje y el surgimiento del sujeto:

Los significantes -las palabras-son lo primero, que bajo ciertas circunstancias, permitirá que emerja el sujeto. Pero, esas palabras que van a hacer emerger al sujeto son los primeros otros que lo rodean: entonces, aparecieron como ocupando el lugar del Otro. Por ejemplo, las palabras que me han permitido convertirme en sujeto son en principio las de mis padres. Dicho de otro modo, el futuro sujeto -recordemos que en este punto el sujeto no es todavía verdaderamente sujeto- que no lo será sino en una retroacción [après-coup], después de haber pasado por las palabras del Otro, es sujetado por el sistema del lenguaje, por los significantes del Otro. (Lebrun, 2019, p. 45)

Este término de Otro designa entonces lo que produce la subjetivación. El humus humano surge durante un proceso en el que cada uno se somete, a la vez que empieza a poder sostenerse con el significante. Fue Lacan quien por primera vez subrayó la alteridad del lenguaje, por lo cual lo denominó Otro con mayúscula.

\section{Palabra y enseñanza}

Los modernos, en general, y los educadores, en particular, habían sido advertidos sobre la importancia de la palabra, no por teorías sino por experiencias contundentes. El primero de esos casos fue el de los niños que murieron luego de haber sido criados por nodrizas desde su nacimiento, con la consigna de no hablarles jamás, según la intención del emperador germano Federico II Hohenstaufen en el siglo XIII, quien pretendía resolver por esa vía su pregunta de cuál era la lengua fundamental. El segundo, tuvo lugar en 1800, cuando fue hallado un niño en los bosques de Caune, cerca de los Pirineos franceses, quien al parecer estuvo por años en estado de naturaleza, sin contacto humano; es decir, sin haber sido sometido por los significantes. Su caso ha sido el más célebre de los llamados niños salvajes, posiblemente a causa de las incursiones educativas y experimentos de Jean Marc Gaspard Itard, considerado pionero de la educación especial, a pesar de las múltiples críticas a sus métodos de domesticación (Mannoni, 1969, pp. 138-150).

Poco después, en 1818, tuvo lugar la experiencia de Joseph Jacotot, profesor de literatura francesa, quien por una circunstancia del azar fue llevado a observar que sus estudiantes pudieron aprender la lengua francesa sin explicaciones, simplemente usando una versión bilingüe del Telémaco, de Fenelón, que les proveyó y su lengua materna, el holandés. Jacques Rancière (2007) analiza en El maestro igno- 
rante las incidencias políticas de la labor del maestro, a partir de esa experiencia de Jacotot. Se radicaliza en contra de la pendiente del maestro explicador al cual considera un agente del embrutecimiento, ya que se sostendría con una supuesta desigualdad de las inteligencias; esto es, con la superioridad de una inteligencia que sometería a otra inferior.

Los alumnos [de Jacotot] habían aprendido sin maestro explicador, pero no sin maestro. Antes no sabían y ahora sí. Por lo tanto, Jacotot les había enseñado algo. Sin embargo, no les había transmitido nada de su ciencia. En consecuencia, no era la ciencia del maestro lo que el alumno aprendía [...] había retirado su inteligencia del juego, permitiendo que la inteligencia de sus alumnos se enfrentara con la del libro. [...] se habían separado [...] las dos facultades en juego en el acto de aprender: la inteligencia y la voluntad: relación de dominación del maestro que había tenido como consecuencia una relación enteramente libre de la inteligencia del alumno con la del libro, esa inteligencia, que además era la cosa común, el vínculo intelectual igualitario entre el maestro y el alumno. (Rancière, 2007, p. 28)

El método de la Enseñanza universal de Jacotot, que Rancière (2007) expone como un método de emancipación de la inteligencia, va en el sentido de promover cierta separación del sujeto respecto de los significantes del Otro, al menos del Otro encarnado en el maestro, cuya palabra impuesta corre el riesgo de adoctrinar, de reforzar la alienación, la adhesividad hacia la persona del maestro, que no moviliza su inteligencia. Curiosamente, en esa separación de inteligencia y voluntad, la función del maestro queda del lado de esta última:

Hay embrutecimiento allí donde una inteligencia está subordinada a otra inteligencia. El hombre -y el niño en particular- puede necesitar un maestro cuando su voluntad no es lo suficientemente fuerte para ponerlo y mantenerlo en su camino. Pero, esta sujeción es puramente de voluntad a voluntad. (p. 28)

El énfasis de Rancière en que el maestro debe evitar el adoctrinamiento y eludir la subyugación de la inteligencia, viene al encuentro de los límites que Lacan sitúa a la enseñanza cuando habla del lugar del sujeto en ella y del modo en que este sujeto circula por los diferentes lugares del discurso. Vale aclarar que el discurso en Lacan está constituido como un algoritmo. Lacan afirma que el discurso es un modo de vínculo social y continúa la serie de tareas imposibles que Freud había señalado: gobernar, educar y psicoanalizar. Adicionalmente, añade la que se impone a la histérica de hacer desear, y las sitúa como cuatro vínculos sociales, como cuatro relaciones de dominación. Elabora sus versiones topológicas, cuya lógica está dada por el lugar que ocupe cada uno de sus cuatro elementos:
$\mathrm{S}_{1}, \mathrm{~S}_{2}$ (significantes que se articulan en cadena), \$ sujeto y objeto $a$. He aquí el nombre de los cuatro lugares del algoritmo de un discurso:

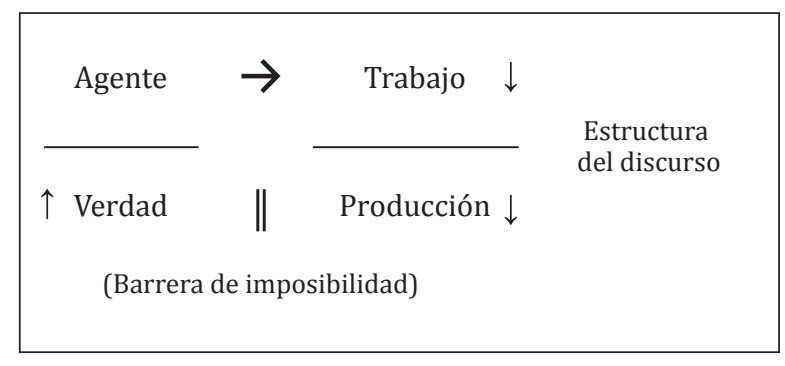

La influencia entre lugares está indicada por las flechas, en sentido único. Ese flujo es cortado por un límite, imposibilidad situada entre la verdad del agente (abajo a la izquierda) y el lugar de la producción (abajo a la derecha). Entre los dos lugares existe || una barrera.

Uno de los cuatro discursos que Lacan formuló en su seminario sobre El reverso del psicoanálisis, dictado de 1969 a 1970, es el que está comandado por el saber $\left(\mathrm{S}_{2}\right)$. Sin embargo, el propio Lacan (2012) lo acusó de ser el más oscurantista y de guardar la tiranía en el lugar de su verdad. En sus comentarios a la enseñanza advierte que "saber algo, no implica que se lo enseñe" (p. 320) y que "una enseñanza no significa que les haya enseñado nada, que de ella resulte un saber" (p. 317). En ocasiones incluso la enseñanza puede erigirse en "el obstáculo para que el sujeto sepa lo que dice” (p. 318), pues admitiendo todo su decir, una enseñanza puede negar escucha al saber del sujeto.

Existe pues una fractura entre saber y enseñanza, esta última tropieza con el hecho que señala Lacan (2012): "no puedo ser enseñado más que en la medida de mi saber" (p. 319). Punto en el cual hay algún encuentro con la denuncia del "explicador", como agente de embrutecimiento, que hace Rancière.

Esas experiencias muestran que la palabra permite a una generación humanizar a la siguiente, y a la vez la separación de la palabra transmitida, o si queremos decirlo de otro modo, muestran la importancia de la pérdida en la transmisión. Lo que Rancière llama emancipación ocurre, según él, a condición de considerar la igualdad y el deseo:

A través de la experiencia del niño, del sabio y del revolucionario, el método del azar practicado con éxito por los estudiantes holandeses revelaba su segundo secreto: Aquel método de la igualdad era antes que nada un método de la voluntad. Se podía aprender, cuando se lo quería, solo y sin maestro explicador mediante la tensión del deseo propio o la exigencia de la situación (Rancière, 2007, p. 27). 
Rancière habla de la tensión del deseo propio de exigencia en el acto de aprender. Algo muy distinto al panorama armónico, divertido, lúdico, que pretende la moralidad educativa de hoy. También lo que descubre Freud es disarmónico, pues el hombre tiene problemas con su deseo, no lo quiere, se defiende de él, incluso mediante esas defensas construye síntomas. Sin embargo, los ideales pedagógicos de hoy, la moral social actual, no distinguen los señuelos del deseo del deseo mismo. Señuelos que circulan por la lógica del discurso imperante. El psicoanalista Marie-Jean Sauret (2018) hace una revisión de distintos momentos en la elaboración de Lacan sobre este concepto en el artículo “¿Existe el Otro?”: "Lo que [Lacan] precisa al final de 'Subversión del sujeto y dialéctica del deseo' indica que 'la máquina en el sentido moderno [es eso] en lo que puede materializarse la relación del sujeto con el significante"' (p. 167).

Desde el inicio de su enseñanza, en el seminario 2 , cuando desarrolla la teoría psicoanalítica del yo, Lacan habla de una experiencia mecánica, denomina máquina a algo que ya había interpelado a Freud en la clínica: el retorno de experiencias traumáticas, o compulsión de repetición de experiencias dolorosas. Este carácter automático conserva toda vigencia y pertinencia en los análisis de los problemas de la sociedad contemporánea y particularmente la "baja autoestima" de la cual se quejan los jóvenes con frecuencia. Pero la depresión no se explica — señala el filósofo surcoreano Byung-Chul Han- por una baja autoestima, como acusan los sujetos, más bien es producida por la máquina, es efecto de los imperativos y la lógica del discurso capitalista, ese " ¡Cuando tienes que tenerlo, tienes que tenerlo!". Es decir, narcisismo puro, que niega el deseo y el amor capaz de dirigirse al otro, en tanto atopos.

La libido se invierte toda en la propia subjetividad. El narcisismo no es ningún amor propio. El sujeto del amor propio emprende una delimitación negativa frente al otro, a favor de sí mismo. En cambio, el sujeto narcisista no puede fijar claramente sus límites. De esta forma se diluye el límite entre él y el otro. El mundo se le presenta solo como proyecciones de sí mismo. No es capaz de reconocer al otro en su alteridad [...]. La depresión es una enfermedad narcisista. [...] Eros y depresión son opuestos. El Eros arranca al sujeto de sí mismo y lo conduce fuera, hacia el otro. El actual sujeto narcisista del rendimiento está abocado, sobre todo, al éxito (Han, 2014, p. 11).

Este autor confirma que la experiencia ha confirmado muchas de sus observaciones sobre el malestar en la civilización. Muchos quieren ver la solución en la eficiencia de los educadores para que incrementen el saber; en suma, promulgan imperativos de progreso y crecimiento. En otro sentido, la vida del planeta muestra daños irreversibles, la extinción también nos amenaza y no pocos esperan que la educación señale los límites necesarios.

\section{Pero, ¿puede educarse la máquina de la repetición?}

Para empezar, ¿de qué máquina hablamos? ¿De qué modo se echa a andar esa máquina? ¿Cómo funciona? No tomo en cargo aquí esas preguntas. Me ocuparé de la sujeción por el lenguaje tal como indica la experiencia del psicoanálisis, para interrogar si la educación podría tener allí o no participación.

Desde la construcción del grafo en Las formaciones del inconsciente, de 1957, Lacan avanza hacia la causación del sujeto, y en 1964, en el seminario 11, Los cuatro conceptos fundamentales del psicoanálisis, puntualiza dos momentos de la relación constitutiva del sujeto en la cadena significante: momentos de alienación y separación.

La alienación de la que habla no es la que encontramos en la filosofía, no es la desposesión de sí mismo, en la que la actividad realizada convierte al individuo en otra cosa diferente a la que él es, como la concibió Hegel. Lacan muestra de qué modo, a partir del campo del Otro, surge el sujeto como en la teoría de conjuntos, representemos a uno y otro mediante los aros de Euler.

\section{Figura 1. Aros de Euler}

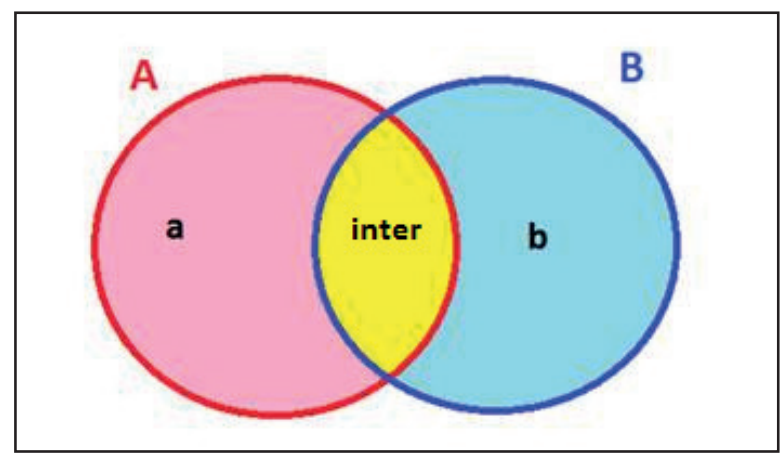

Fuente: Elaboración propia.

En la figura 1, A representa el campo del Otro; a saber, el conjunto de los significantes de la lengua materna de la cual toma sus significantes el sujeto B. Si este es todavía infans, sin palabra, admitiremos que B toma los mismos significantes que formula A, representados por la zona amarilla del gráfico. Lo común entre А у в, el inter en la figura, estaría dado por los mismos significantes: la reunión de los dos conjuntos, que define la alienación lacaniana. 
Pero, en un segundo momento, el mismo significante pronunciado por el Otro materno A, al ser escuchado por el sujeto B, resulta modificado. Lo cual opera la separación del sujeto в (figura 2).

Figura 2. Aros de Euler

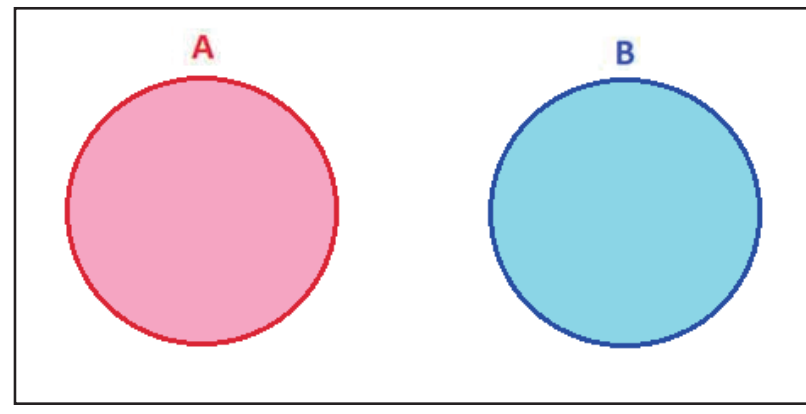

Fuente: Elaboración propia

Recordemos que los aros representan no solo los significantes del Otro y del sujeto, sino los vivientes que los soportan. El Otro, la cadena significante, requiere del viviente que la articula, sin el cual el Otro estaría desactivado. Es esta sustancia viviente la que permite la separación y el surgimiento de un elemento no significante. A ese elemento no significante propio de lo vivo Lacan lo llamó objeto $a$, surgido como residuo, como pérdida al separarse el Otro y el sujeto. Vale decir que la transmisión humana, la transmisión del lenguaje no es sin pérdida, el criador no transmite una copia exacta de un código al nuevo organismo, al niño. "Con respecto al animal somos máquinas -dice Lacan-, es decir algo descompuesto, pues manifestamos más libertad, posibilidades de elección" (1978b, p. 44).

En virtud de esas posibilidades de elección, una cura analítica busca precisamente la separación entre el sujeto y el Otro. Lo cual no obsta para que antes de cualquier cura el sujeto se haya distanciado de criadores y educadores, representantes del Otro. Además, la educación enfrenta dos riesgos que pesan sobre el joven sujeto: 1) sus propias crisis (infantiles $\mathrm{y}$ adolescentes) mientras se hace un lugar entre sus contemporáneos y se inscribe en la cultura; 2) resistir a las ofertas de cohesión con otros mediante la segregación y el odio ${ }^{1}$.

En el debate sobre el suicidio, Freud (1910 [1982]) dice lo que se esperaría en ese tiempo:

1 Luego de la elección presidencial en Colombia, se han intensificado las ejecuciones y amenazas a líderes populares, provenientes de oscuros poderes económicos, empresariales y políticos.
[...] la escuela media tiene que conseguir algo más que no empujar a sus alumnos al suicidio; debe instilarles el goce de vivir y proporcionarles apoyo, en una edad en que por las condiciones de su desarrollo se ven precisados a aflojar sus lazos con la casa paterna y la familia (pp. 231-232).

Sin embargo, desde los tiempos de Freud la vida ha cambiado y en el llamado tercer mundo la educación primaria ni siquiera es universal ni obligatoria. En este país, debido a la explotación infantil, al reclutamiento por grupos armados, al embarazo precoz (desde los 8 años y el promedio se ubica en los 11), entre otros, terminar la educación media deviene un privilegio. Cada año, 5000 jóvenes, muchos aún en el duelo y las crisis del despertar adolescente se hacen bachilleres, a la espera de acceder a la formación superior. Pero, no hay cupos para todos, tampoco hay empleo. Son los nini: ni estudian ni trabajan, de ahí que con frecuencia caigan en goces y formaciones grupales mortíferas.

Freud pide a la escuela que sea "un sustituto de la familia". De acuerdo con Morin (2015): "la familia es el crisol originario que perpetúa la primera relación de amor al saber supuesto al Otro [sin embargo,] también donde los odios y los celos encuentran su punto de partida y su consistencia" (p. 204). Hace años, cuando multitud de gamines comían desperdicios, dormían bajo papel periódico y vivían en las calles de Bogotá, nadie dudaba de la falta de familia y en particular de función materna. Hoy el capitalismo ofrece sustitutos maternos, que bajo mayor satisfacción y confort que los que pudo proveer la familia, oculta su tiranía. En términos de Han (2014):

La coacción engendrada por uno mismo se presenta como libertad, de modo que no es reconocida como tal. El tú puedes engendra más coacción que el tú debes. [...] El régimen neoliberal esconde su estructura coactiva tras la aparente libertad del individuo, que ya no se entiende como sometido (subjectto), sino como desarrollo de un proyecto (p. 21).

Por su parte, Hannah Arendt alude al ejemplo de las Lebensborn (maternidades de las Ss) facilitadas por la ley de emancipación precoz de los adolescentes arios alemanes, para quitar la patria potestad de sus padres, que estorbaba su reducción a instrumentos en los propósitos de manipulación eugenésica del III Reich.

El papel desempeñado por la educación en todas las utopías políticas desde los tiempos antiguos, muestra lo natural que parece el hecho de empezar un nuevo mundo con los que por nacimiento y naturaleza son nuevos [...] una intervención dictatorial basada en la absoluta superioridad del adulto, que intenta presentar lo nuevo como fait accompli, es decir, como si lo 
nuevo ya existiera. [...] La idea de que quien quiera producir condiciones nuevas debe empezar por los niños, fue monopolizada por los movimientos revolucionarios de corte tiránico: cuando al llegar al poder arrebataban los niños a sus padres y sencillamente los adoctrinaban (Arendt, 1996, p. 188).

La crítica de Arendt no solo nos remite a un momento histórico concreto que muestra con cuánta facilidad los sujetos más jóvenes son manipulados, sino también cómo la crisis en la educación es el riesgo de su degradación, de devenir mera sugestión, seducción, indulgencia o un dar gusto al capricho, sin razones de supervivencia y crecimiento.

En principio, la escuela no cumple tales funciones, más bien separa o debe separar al sujeto de los primeros vínculos (materno, fraterno), para plantearle que son posibles formas más amplias de lazo social. En ese sentido, la escuela no sustituye a la familia, sino que propicia en el sujeto cierto nivel de ruptura con ella, por eso debería posibilitar encuentros entre los diversos sujetos e impulsarlos a inscribirse en ese mundo que pretende presentarles, tal como es, con todos sus problemas.

Si admitimos el proceso descrito, un profesor no tendría ningún acceso al proceso inaugural de sujeción, de causación del sujeto en el seno familiar. Ese primer paso de sometimiento al lenguaje (alienación) efectuado con el gran Otro materno (Otro de la crianza) solo se haría inteligible por el propio sujeto en una cura analítica. Ni la escuela ni los profesores pueden remediar los efectos de la alienación ya realizada en cada joven sujeto al aprender a hablar. Tampoco puede el educador evitar ni ahorrar al sujeto los efectos nocivos que el capitalismo pueda ejercer sobre él. Sin embargo, estos esclarecimientos aportados por la práctica analítica no son admitidos por las actuales políticas educativas. El sujeto aparece como excluido de su propia vida. De acuerdo con un documento de formación docente del Ministerio de Educación Nacional (s.f.):

La política de formación docente en Europa se fundamenta en la concepción de la educación como factor determinante del desarrollo humano y la calidad de vida. Se reconoce que el desarrollo del talento humano de niños, niñas y jóvenes recae esencialmente en los docentes, y por ello su formación académica, científica y técnica ${ }^{2}$ cobra una importancia capital

2 Aquí aparece la formación del profesor, como la garantía del destino del talento de los jóvenes sujetos a su cargo. Se comprende bien que las premisas que subyacen a esta afirmación son: primero, que existe una transmisión sin falta y, segundo, que la autenticación de algunos conocimientos garantizaría de inmediato el vínculo educativo y la relación con el saber, sin dar ningún lugar al deseo de cada sujeto. para los distintos gobiernos nacionales y para la comunidad europea en su conjunto, como organización que proyecta la acción hacia el futuro (p. 3).

Adicionalmente, la prominente inequidad social actual en Colombia invalida cualquier logro por méritos, el destino del talento de los jóvenes es forzado por la clase social, la etnia, la ubicación geográfica, etc. En 2018 recibimos el anuncio de que se rebajaron los exiguos recursos del 0,3\% del PIB destinados a investigación y desarrollo a 0,24\%, mientras en 2017 la República de Corea gastó el 4,55 \%; EE UU 2,79 \%; los miembros de la oCDE 2,56 \% y Europa y Asia Central habían gastado 1,89 \% en ese año (GBM, 2018).

Evidentemente, la democracia no se reduce al voto ni a las elecciones, depende más de que los impuestos se gasten en lo que un colectivo necesita. No consiste - como ocurrió con el polémico programa de becas "Ser pilo paga", auspiciado por el Ministerio de Educación Nacional- en que el Estado compre con dinero público cupos a universidades privadas, al precio que estas imponen y diga que los distribuye por méritos, si desde la cuna, la gran mayoría de la población está privada de todas las oportunidades de vida propicia para las realizaciones.

No obstante, las elecciones del año 2018 en Colombia confirmaron en la Presidencia del país a una plutocracia sin proyecto colectivo de nación, regida por intereses empresariales, agroindustriales, de explotación minero-energética y megaproyectos de construcción, como la represa de Hidrohituango que ocasionó daños irreparables al caudal del río Cauca; la caída del puente Chirajara, o el segundo tramo de la Ruta del Sol, involucrado en la filtración de dineros de Odebrecht a las campañas de elección presidencial, donde los particulares no solo saquean al erario público, sino compran a su antojo la voluntad de los gobernantes. La complicidad obediente del pueblo revela a cada uno imposibilitado para separarse de los significantes del Otro, un sujeto dispuesto a seguir en la alienación, estancado en la alienación al Otro.

Temo que aconsejar a la escuela instilar el gusto de vivir a los jóvenes es interpretado hoy como ofrecerles sustitutos libidinales y alimentar la autoestima, el narcisismo. Si la escuela dice al sujeto lo maravilloso que es, redoblando lo que dice la familia, significa continuar la alienación del sujeto, ya garantizada por el hecho de que al inicio de su vida siempre es hablado por otro.

La separación del Otro, en cambio, solo surge cuando el significante dicho es distinto al ser el significante escuchado por el sujeto (aros de Euler). 


\section{La sujeción sin separación y lo social sin lazo}

En otro artículo "Los horrores de masas y la obediencia incondicional", Morin (2014) muestra como motor de las acciones de los nazis Franz Stangl y Adolph Eichmann, su imposibilidad para separarse de las palabras del Otro:

Los sujetos de los cuales hablamos son frecuentemente sujetos cualesquiera, ordinarios en el sentido de que no han realizado nada de importancia, nada de gran envergadura intelectual, y de quienes se puede pensar que, en tiempos ordinarios, no habrían cometido crímenes. No los asimilo a los criminales contra los cuales la sociedad se defiende mediante lo judicial. Por lo demás, en lo que concierne a sus crímenes, se ha requerido instituir tribunales de excepción pues es necesario probar que, más allá de una obediencia a la que se creían sometidos, esos sujetos tuvieron la posibilidad de decir no y no lo hicieron, por el contrario, fueron a menudo ejemplares en el trabajo bien hecho (p. 110).

Morin advierte que ellos no habrían sido criminales si no fuera por la máquina a la que obedecieron. Luego, ofrecer una formación en el conocimiento y la conciencia de buena conducta no asegura nada contra el actuar inhumano.

Por su lado, en "Psicología de masas y análisis del yo", Freud (1982) cita a otros autores interesados como él en el fenómeno de masas, y avanza sobre esa revisión su formulación de la estructura de la masa a partir de su teoría de las identificaciones y de la dinámica libidinal en la sugestión, tanto en la hipnosis, como en las relaciones amorosas.

\section{Figura 3. Estructura de la masa}

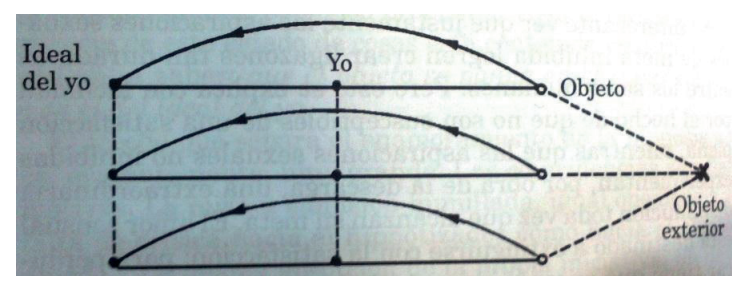

Fuente: Freud (1921 [1982], p. 110).

En la figura 3, propuesta por Freud, las líneas horizontales representan a cada uno de los miembros de la masa, que en su historia particular se ha construido una imagen de sí, un yo, así como su Ideal del yo y erigido un objeto libidinal propio. Como muestran las líneas paralelas del gráfico, cada miembro está desligado de los otros en la masa; pero, el fenómeno libidinal, la masificación, ocurre porque cada uno proyecta en un objeto exterior (líder, objeto, panta- lla, televisión) su propio objeto y (como indican las flechas de sentido retrógrado) lo erige en su propio Ideal del yo, mientras asume una identificación imaginaria (líneas punteadas entre cada yo) con los demás miembros del colectivo.

En una masa los individuos están ante una relación pulsional con un objeto externo que sostiene la ilusión de relación con otros, la cual desaparece al eclipsarse el objeto. En otros términos, nuestras organizaciones colectivas del presente, tan proclives a la formación de masas, están desvirtuando lo que podríamos llamar propiamente sociedad. En la masa no hay lazo social.

Lo social se constituye a veces contra el lazo social. El lazo social, tal como el psicoanálisis lo concibe, es lo que une a los hablantes-seres entre sí, con vistas a renovar lo vivo y a hacer obra en la civilización. Unir no es desunir y, por eso, para la destrucción de lo vivo deberíamos inventar otro término que hiciera resonar la pulsión de muerte puesta al servicio de la desmezcla de las pulsiones (Morin, 2015, p. 104).

\section{Un caso de la historia en Colombia}

Como ejemplo local cito a la familia de líderes paramilitares Castaño Gil, según el relato de Manuel Castaño Gil, uno de los dos supervivientes de diez varones, de los catorce hermanos campesinos de Amalfi, ninguno cursó más de dos, a lo sumo tres años de escuela, aunque mostraron su inquietud por el trabajo bien hecho, según el Otro constituyente en la familia. Recordemos que fueron fundadores de las Autodefensas Unidas de Colombia (AUC) y ejecutaron varias masacres en Córdoba y Urabá.

En la entrevista a Manuel Castaño Gil (2018) relata que: "Cuando José Vicente, el mayor, murió de neumonía, a los 7 años mi madre dijo: 'Mejor que ese se haya muerto, porque ese iba a dañar la raza"'.

La frase de doña Rosa remite a los años 1920, cuando el entonces presidente Laureano Gómez declaró necesario casarse con alemanes para "mejorar la raza indígena degenerada". En la frase de doña Rosa es la muerte lo que aparece como solución.

Mi segundo hermano, Fidel, jugaba a los naipes y ganaba con cartas marcadas en el pueblo. Mi papá le advertía a la gente que Fidel los iba a robar y una vez pelearon a bala en la plaza del pueblo. Entonces Fidel se fue a las minas de diamantes de Guyana y prometió que al volver compraría el pueblo con la plata del bolsillo. ¡Y así fue! Cuando volvió a los 16 años ya era el más rico del pueblo. ¡Fidel era un banco de hacer plata! Yo mismo le conté que el pre- 
sidente Mariano Ospina Pérez fue el que sacó más oro aquí y llegó a tener 100.000 hectáreas de tierra en la región del Sinú. ¡Y eso lo hizo matando indios! Entonces, Fidel me dijo: "Yo voy a hacer como él".

Recordemos que Fidel Castaño, alias Rambo, lideró el exterminio de la Unión Patriótica (UP) y numerosas masacres, su "matar indios" para "hacer como el Otro" revela una no-separación del Otro.

Manuel termina su relato manifestando orgullo sobre su cuarto hermano: "Luego viene Carlitos, él dejó la escuela en tercero, ¡cuando tenía 12 años y a los 15 ya era un caporal!".

Carlos Castaño recibió entrenamiento militar en Israel, tenía vínculos con agentes de la DEA y la CIA y recreaba el delirio de ser un coronel del ejército, dándose una misión militar. Tomó el lugar de Fidel y limpió la región con Vicente Castaño y "Doblecero", por medio de descuartizamientos y hornos crematorios. Tiempo después fue asesinado a su vez por su hermano Vicente, luego de su desmoronamiento psíquico cuando su única hija nació con el síndrome de Lejeune ${ }^{3}$, lo que él interpretó como una señal de Dios. ¿No parece acaso la aparición en lo real de lo no simbolizado, de ese significante tomado del Otro que es la raza degenerada?

La muerte violenta de ocho de los diez varones y una de las cuatro hijas Castaño Gil a manos de su propio hermano interroga la transmisión de estos significantes de raza y muerte en estos sujetos carentes de mediación escolar. A propósito de la muerte del hijo, el psicoanalista antioqueño Mario Elkin Ramírez (2000) señala tres rasgos reiterativos en la relación entre el sicario y su madre: 1) el culto de la matrona antioqueña como madre-virgen, 2) el padre suplantado ante ella por el hijo y 3) la inmolación de este último. Por su parte, la mexicana Laura Esquivel (1989), en su novela Como agua para chocolate, muestra cierta tradición latinoamericana, en la cual la madre destina la vida de una hija o un hijo, a su exclusivo servicio hasta la muerte. Y García Márquez (1985) dedica «Al cocodrilo sagrado» Los funerales de la mamá grande, donde describe el culto a LA mujer ${ }^{4}$, virgen-madre y mártir no deseante. ¿Lo peor de la religiosidad tecnocapitalista?

3 Alteración del brazo corto del cromosoma 5, que se caracteriza por producir microcefalia, múltiples malformaciones faciales, corporales y un característico llanto en maullido de gato.

4 El artículo definido $L A$ fue escrito por Lacan en mayúsculas para designar que lo que no existiría es el universal de la mujer, completa, absoluta, designada por el oxímoron Virgen/ Madre, o también cuando alguna juega a constituirse en amo del amo, está el neologismo de Lacan: l'hommosexuelle cuya traducción literal al español sería la hombresexual.

\section{La separación por la palabra}

La alienación es garantizada porque ello habla del sujeto, pero lo que permite la separación es la diferencia entre el significante pronunciado por el Otro y el mismo significante escuchado por el sujeto. Si quien enseña es el sujeto (Lacan, 2012) este tiene que tomar la palabra, entonces, la función de la escuela sería procurar que lo haga y escucharlo, dar un lugar a su palabra. Antaño la escuela exigía silencio, hoy son los chicos quienes prefieren no hablar. Y, ¿qué implica hacerlo o no?

El adolescente dice que hablar lo angustia, aunque sabemos con Freud que esta no engaña, por cuanto es señal inequívoca del objeto. En el artículo "Lo verdadero hace falta", que circuló entre los miembros de la Association Psychanalytique Jacques Lacan en 2007, Pierre Bruno ratifica la aparición de la angustia, por la caída del objeto en la separación entre sujeto y Otro:

El objeto tomado del Otro, es decir, del lugar donde se origina el lenguaje, señala que el Otro gozaría de mí cuando habla, como si yo fuera reducido al enunciado que escucho de él, si no registrara mi irreductibilidad (no quiero ser gozado por el Otro) por el hecho de extraer de este Otro lo que no es significante en él, y esto porque el Otro solo, el Otro sin soporte viviente para hablar, está desactivado (2007, p. 3).

Entonces, hablar implica la aparición de ese resto, objeto no significante, que angustia en tanto separa del Otro, pero justamente comporta la distinción entre el sujeto y el Otro.

La escuela convoca al sujeto de la ciencia, pero, aunque esta "no niegue al objeto a no lo toma en cuenta" (Bruno, 2007, p. 3), pues como ciencia de la naturaleza, no tiene que ver con el ser hablante. En contraste, Pierre Bruno postula una aciencia que concibe del siguiente modo:

Una ciencia que integre el objeto $a$, sería entonces una ciencia en la cual el axioma inicial sería que toda palabra escuchada o pronunciada, produce una des-inclusión de $a$ en el Otro, y eso que es del Otro no puede ser incluido en el sujeto porque no es significante (p. 3).

Esa des-inclusión del $a$ (acompañada de angustia) es ya separación del Otro, afirma Bruno. Desde la apreciación de este artículo, si bien no es la salida que permitiría una cura, quizás un modo de enseñanza dirigida a horadar las certezas primarias del sujeto, operaría una separación preliminar, a condición de inventar estrategias para que el sujeto debata, aprenda a alternar en un colectivo, donde se dé espacio para la formulación y la escucha de la palabra de 
cada joven sujeto. Ni tratar de hacer aciencia ni el que enseña pueden ahorrar al sujeto la angustia de hablar desde el vacío, la función de una enseñanza está en lo que Sócrates evidencia a Menón luego del ejercicio de reminiscencia y cuestionamiento al esclavo; a saber, que ahora está en mejor disposición respecto a la cosa que ignoraba (Platón, 1987).

\section{Referencias}

Arendt, H. (1996). La crisis de la educación. En Entre el pasado y el futuro (pp. 269-301). Barcelona: Editorial Península.

Bruno, P. (2007, 1 de octubre, inédito). Lo verdadero hace falta. En Seminario Science / Ascience. Documento para uso interno de miembros de la Association Psychanalytique Jacques Lacan-APJL.

Esquivel, L. (1989). Como agua para chocolate. México: Penguin Random House.

Freud, S. (1910 [1982]). Contribuciones a un debate sobre el suicidio. En Obras completas (Vol. XI, pp. 231 y 232.). Buenos Aires: Amorrortu Editores.

Freud, S. (1921 [1982]). Psicología de las masas y análisis del yo. En Obras completas (vol. XVIII, pp. 63-136). Buenos Aires: Amorrortu Editores.

García Márquez, G. (1985). Los funerales de la mamá grande. Bogotá: Editorial Oveja Negra.

Grupo Banco Mundial (GBM) (2018). Gasto en investigación y desarrollo. [Tabla en línea]. Recuperado el 1 de mayo de 2020 en https://datos.bancomundial.org/indicador/ GB.XPD.RSDV.GD.ZS

Han, B.C. (2014). La agonía del Eros. Barcelona: Herder Ediciones.

Lacan, J. (1978a). Questions à celui qui enseigne. En Le séminaire Livre II. Le moi dans la théorie de Freud et dans la technique de la psychanalyse (pp. 241-257). Paris: Éditions du Seuil.

Lacan, J. (1978b). L'univers symbolique. En Le séminaire Livre II. Le moi dans la théorie de Freud et dans la technique de la psychanalyse (pp. 39-53). Paris: Éditions du Seuil.
Lacan, J. (2012). Alocución sobre la enseñanza. En Otros escritos (pp. 317-325). Buenos Aires: Paidós.

Lebrun, J.P. (2019). La perversión ordinaria. Bogotá D.C.: Libros de la Espiga.

Mannoni, O. (1969). Itard y su salvaje. En La otra escena. Claves de lo imaginario (pp. 138-150). Buenos Aires: Amorrortu Editores.

Ministerio de Educación Nacional (MEN) (s.f.). Capítulo 1. En Documento de política y sistema de formación docente. [En línea]. https://www.mineducacion.gov.co/1759/ articles-345822_ANEXO_18.pdf

Millot, C. (1979). Freud anti-pédagogue. Paris: Navarin éditeur.

Morin, I. (2014). Los horrores de la obediencia incondicional. Desde el Jardín de Freud, 14, 107-122.

Morin, I. (2015). Las consecuencias de la fobia en el lazo social. Desde el Jardín de Freud 15, 103-113.

Platón (1987). Diálogos II. Menón o de la virtud. 79a7-82b2. Madrid: Editorial Gredos.

Ramírez, M-E. (2000). El sicario y la madre. Aporías de la cultura contemporánea. Medellín: Universidad de Antioquia, pp. 21-29.

Rancière, J. (2007). El maestro ignorante. Cinco lecciones para la emancipación intelectual. Buenos Aires: Libros del zorzal.

Sauret, M-J. (2018, enero-junio). ¿Existe el Otro? (Trad. A. Sotelo). Pedagogía y Saberes, 48, 163-178. https://doi. org/10.17227/pys.num48-7381

Semblanzas (2018, 30 de abril). Entrevista completa a Manuel Castaño Gil por Toño Sánchez Jr. [video en línea]. Consultado el 11 de julio de 2018, disponible en https://www.youtube.com/watch?v=1AjRNoBV4AM 